\title{
Simulasi Pembelajaran Interaktif pada Praktikum Embedded System Berbasis Web
}

\author{
Nenny Anggraini \\ Teknik Informatika, Sains dan Tenologi \\ Universitas Islam Negeri Syarif Hidayatullah Jakarta \\ nenny_anggraini@uinjkt.ac.id
}

Diterima: 9 Maret 2017. Disetujui: 10 April 2017. Dipublikasikan: Mei 2017

\begin{abstract}
Abstrak - Simulasi adalah suatu proses peniruan dari sesuatu yang nyata beserta keadaan sekelilingnya (state of affairs). Aksi melakukan simulasi ini secara umum menggambarkan sifat-sifat karakteristik kunci dari kelakuan sistem fisik atau sistem yang abstrak tertentu. Metode yang dipakai adalah Monte Carlo sebagai alur perancangan simulasi. Simulasi ini mendukung proses pembelajaran mata kuliah embedded system yang ada di Program Studi Teknik Informatika Fakultas Sains dan Teknologi. Simulasi pembelajaran ini menggunakan multimedia interaktif sebagai alat pengontrol yang dapat dioperasikan oleh pengguna melalui web, sehingga pengguna dapat memilih apa yang dikehendaki untuk proses selanjutnya. Dalam mata kuliah embedded system, dengan simulasi seperti ini pengguna dapat melakukan praktikum seperti di laboratorium menggunakan mikroprosesor secara digital. Tujuannya adalah agar pembelajaran tidak terbatas pada waktu, tempat dan ketersediaan alat di laboratorium. Simulasi laboratorium ini berbasis web sehingga dapat dijadikan sebagai cetak biru electronic laboratory
\end{abstract}

Kata Kunci: web, simulasi, Monte Carlo, embedded system; multimedia interaktif.

\section{PENDAHULUAN}

Simulasi adalah suatu proses peniruan dari sesuatu yang nyata beserta keadaan sekelilingnya (state of affairs). Aksi melakukan simulasi ini secara umum menggambarkan sifat-sifat karakteristik kunci dari kelakuan sistem fisik atau sistem yang abstrak tertentu. Sudah lama metode simulasi dipakai sebagai alat penting dalam perancangan, misalnya simulasi perancangan pesawat terbang, sistem komunikasi telepon, pertempuran militer, atau operasi pemeliharaan dalam menentukan ukuran optimal tim operator. Dengan berkembangnya komputer dan bahasa pemrograman menjadikan teknik-teknik simulasi banyak diterapkan secara luas dan diterima sebagai alat dalam sistem analisis dan operasi penelitian [1].

Pembelajaran diartikan sebagai proses penciptaan lingkungan yang memungkinkan terjadinya proses belajar. Dalam pembelajaran yang utama adalah bagaimana siswa belajar. Belajar dalam pengertian aktifitas mental siswa dalam berinteraksi dengan lingkungan yang menghasilkan perubahan perilaku yang bersifat relative konstan.

Multimedia interaktif adalah suatu media interaktif yang dilengkapi dengan alat pengontrol yang dapat dioperasikan oleh pengguna, sehingga pengguna dapat memilih apa yang dikehendaki untuk proses selanjutnya. Contoh multimedia interaktif adalah multimedia pembelajaran interaktif, aplikasi game dll. Apabila kedua konsep tersebut digabungkan maka multimedia pembelajaran dapat diartikan sebagai aplikasi multimedia yang digunakan dalam proses pembelajaran. Dengan kata lain, untuk menyalurkan pesan, pengetahuan, keterampilan dan sikap), serta dapat merangsang pikiran, perasaan, perhatian, dan kemauan yang belajar, sehingga proses belajar terjadi, bertujuan dan terkendali.

Mata kuliah embedded system merupakan mata kuliah wajib bagi mahasiswa program studi Teknik Informatika pada Fakultas Sains dan Teknologi, yang mengambil konsentrasi embedded system. Mata kuliah ini berupa teori dan praktek. Proses pembelajaran praktikum dilakukan di laboratorium digital dan mikroprosesor dengan panduan buku petunjuk praktikum yang telah dibuat oleh dosen pengajar mata kuliah embedded system. (dalam hal ini peneliti sendiri yang membuat buku petunjuk praktikum tersebut). Praktikan (dalam hal ini mahasiwa) melakukan praktikum sesuai dengan ketentuan yang ada dalam buku petunjuk praktikum. Dalam pelaksanaan praktikum, praktikan diharuskan membuat suatu alat yang nantinya dihubungkan dengan komputer untuk selanjutnya diprogram agar alat tersebut berfungsi sesuai dengan yang diinginkan [2].

Berdasarkan pengalaman peneliti dalam mengampu praktikum embedded system, praktikan mengalami kendala dalam merangkai sebuah alat. Hal tersebut dikarenakan belum ada panduan yang bersifat interaktif, yaitu berupa tutorial perakitan alat dan cara mengkoneksikan alat tersebut dengan computer. Disamping itu praktikan juga belum dapat mensimulasikan alat yang mereka rancang 
sebelum mereka melakukan perakitan yang sebenarnya. Tidak adanya tutorial dan simulasi ini bisa berakibat fatal terhadap peralatan dan komponen praktikum, yaitu bisa menyebabkan kerusakan komponen dan alat-alat praktikum yang digunakan dikarenakan salah merangkai alat.

Masalah lain yang timbul pada praktikum embedded system ini adalah terbatasnya waktu pengerjaan rangkaian karena waktu praktikum hanya satu setengah jam sehingga seringkali praktikan belum selesai mengerjakan rangkaian tetapi waktunya sudah habis. Praktikan sangat berharap dapat melanjutkan pembuatan rangkaian tetapi dengan memakai tutorial. Berdasarkan uraian diatas, peneliti mempunyai ide untuk membuat sebuah simulasi pembelajaran interaktif praktikum embedded system yang berbasis web, sehingga bisa menjawab semua kendala yang ada pada praktikum embedded system.

\section{LANDASAN TEORI}

\section{A. Simulasi}

Dasar dari simulasi adalah untuk membangun alat eksperimen atau simulator yang akan menirukan semua sistem yang menitikberatkan pada aspek penting yang cepat dan biaya yang efektif [3]. Simulasi adalah proses perancangan model dari suatu sistem nyata dan pelaksanaan eksperimen-eksperimen dengan model ini untuk tujuan memahami tingkah laku sistem [4]. Simulasi sebuah sistem adalah pengoperasian dari sebuah model suatu sistem. Sebuah Model dapat dikonfigurasi dan dilakukan percobaan. Simulasi digunakan sebelum sebuah sistem dibangun untuk mengurangi kemungkinan kegagalan, menghilangkan kemacetan tak terduga, mencegah under atau over pemanfaatan sumber daya, dan untuk mengoptimalkan kinerja sistem. Simulasi dapat didefinisikan sebagai program yang dibangun dengan model matematika berdasarkan pada sistem aslinya yang mempunyai kemampuan untuk memprediksi perilaku dari sebuah sistem di bawah sekumpulan kondisi pengoperasian yang ditetapkan dan dan asumsi penyederhanaan [5]. Menurut Law \& Kelton struktur top down simulasi adalah seperti pada Gambar 6 .

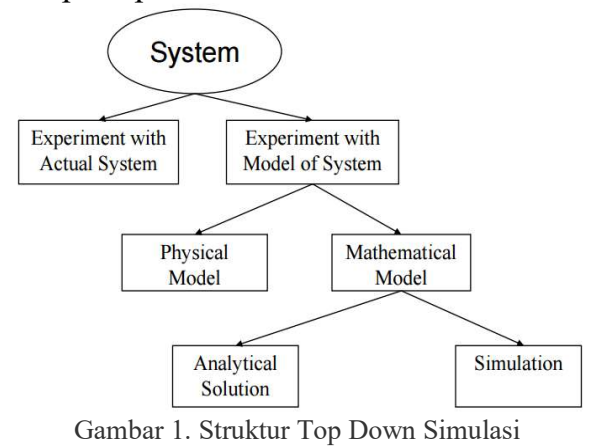

Rasionalisasi mendasar penggunaan simulasi adalah pengetahuan manusia tentang masa yang akan datang. Situasi yang dapat disimulasikan dengan komputer diantaranya sebagai berikut [7].

1) Apabila perolehan data dari proses tertentu dalam dunia nyata biayanya terlalu mahal atau bisa jadi sangat sulit, maka simulasi dapat diterapkan. Misalnya kinerja mesin roket, pengaruh pemotongan pajak terhadap sistem perekonomian, pengaruh advertising terhadap penjualan total produk, dan lainnya.

2) Sistem yang diamati begitu kompleks sehingga tidak dapat diformulasi ke dalam bentuk persamaan matematis yang solusinya analitis, seperti sistem perekonomian atau sistem pendidikan. Dalam hal ini, simulasi menjadi alat paling efektif dalam menyelesaikan masalah-masalah seperti itu.

3) Apabila biaya terlalu mahal atau tidak mungkin untuk memvalidasi percobaan tentang model matematis dalam menjelaskan sistem, maka dalam kasus ini kita dapat mengatakan bahwa data simulasi dapat digunakan sebagai alternatif pengujian hipotesis.

\section{B. Metode Monte Carlo}

Ide pertama dicetuskan Enrico Fermi di tahun 1930an. Pada saat itu para fisikawan di Laboratorium Sains Los Alamos sedang memeriksa perlindungan radiasi dan jarak yang akan neutron tempuh melalui beberapa macam material. Namun data yang didapatkan tidak dapat membantu untuk memecahkan masalah yang ingin mereka selesaikan karena ternyata masalah tersebut tidak bisa diselesaikan dengan penghitungan analitis.

Hal yang berbeda dari simulasi Monte Carlo adalah membalikkan bentuk simulasi yang umum. Metode ini akan mencari kemungkinan terlebih dahulu sebelum memahami permasalahan yang ada. Sementara umumnya menggunakan simulasi untuk menguji masalah yang sebelumnya telah dipahami. Walaupun pendekatan terbalik ini sudah ada sejak lama, namun baru setelah metode Monte Carlo populer pendekatan terbalik diakui [8].

Penggunaan metode paling awal diketahui digunakan oleh Enrico Fermi di tahun 1930. Pada waktu itu beliau menggunakan metode acak untuk menghitung sifat dari neutron yang baru ditemukan. Baru setelah komputer pertama diperkenalkan sekitar tahun 1945 metode Monte Carlo mulai dipelajari lebih lanjut. Metode ini telah digunakan di bidang fisika, kimia fisika, dan lain-lain. Rand Corporation dan U.S. Air Force merupakan sponsor utama dalam pengembangan metode Monte Carlo pada waktu itu dan metode ini semakin berkembang di berbagai bidang. 
Penggunaan metode Monte Carlo membutuhkan sejumlah besar angka acak. Seiring dengan berkembangnya metode ini, berkembang pula pseudorandom number generator yang ternyata lebih efektif digunakan daripada tabel angka acak yang terlah sebelumnya sering digunakan untuk pengambilan sampel statistic [9]. Simulasi Monte Carlo adalah jenis simulasi yang mengandalkan Perulangan random sampling dan analisis statistik untuk menghitung hasil. Metode simulasi sangat erat kaitanya dengan percobaan acak [7].

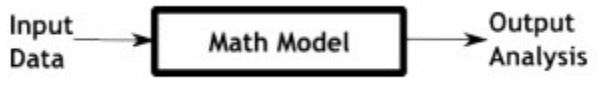

Gambar 2. Model Input Output Monte Carlo

Model ini biasanya tergantung pada jumlah parameter input, yang ketika diproses melalui rumus matematika dalam model. Suatu model memerlukan parameter input dan beberapa persamaan yang digunakan untuk menghasilkan output (atau variabel respon). Dengan menggunakan parameter input berupa bilangan random, maka dapat mengubah suatu model deterministik menjadi model stokastik. Model deterministik merupakan suatu model pendekatan yang diketahui dengan pasti, sedangkan model stokastik tidak pasti.

Simulasi Monte Carlo adalah metode untuk menganalisa perambatan ketidakpastian. Tujuannya adalah untuk menentukan bagaimana variasi random atau error mempengaruhi sensitivitas, performa atau reliabilitas dari sistem yang sedang dimodelkan. Simulasi Monte Carlo digolongkan sebagai metode sampling karena input dibangkitkan secara random dari suatu distribusi probabilitas untuk proses sampling dari suatu populasi nyata. Oleh karena itu, suatu model harus memilih suatu distribusi input yang paling mendekati data yang dimiliki [7].

Hubungan input-output proses transformasi bertujuan untuk mengetahui kerja system. Karakteristik metode simulasi Monte Carlo [7] adalah spesifik, realistik, operasional, relevan dengan nilai nilai pengambil keputusan, menimbulkan resiko pembaruan, terukur keberhasilan yang dicapai, berbatas dengan waktu ada masa berlaku, handal sehingga dapat menjadi dasar dalam penerapan di lapangan.

\section{Pembelajaran Interaktif}

Pembelajaran interaktif dikelompokkan menjadi: 1) media berbasis telekomunikasi misal teleconference, kuliah jarak jauh, dan 2) media berbasis mikroprosesor, misal computer-assistted instruction, permainan komputer, sistem tutor intelejen, interaktif, hypermedia, dan compact (video) disc [10].

Pembelajaran interaktif adalah suatu sistem penyampaian pengajaran yang menyajikan materi video rekaman dengan pengendalian komputer kepada penonton (siswa) yang tidak hanya mendengar dan melihat video dan suara (visual) tetapi juga memberikan respon yang aktif, dan respon itu yang menentukan kecepatan dan sekuensi penyajian. Multimedia interaktif adalah suatu multimedia yang dilengkapi dengan alat pengontrol yang dapat dioperasikan oleh pengguna. Pengguna dapat memilih apa yang dikehendaki untuk proses selanjutnya. Contoh multimedia interaktif adalah multimedia pembelajaran interaktif, aplikasi game, dll. Sedangkan pembelajaran diartikan sebagai proses penciptaan lingkungan yang memungkinkan terjadinya proses belajar. Jadi dalam pembelajaran yang utama adalah bagaimana siswa belajar [10].

Belajar dalam pengertian aktifitas mental siswa dalam berinteraksi dengan lingkungan yang menghasilkan perubahan perilaku yang bersifat relatif konstan. Dengan demikian aspek yang menjadi penting dalam aktifitas belajar adalah lingkungan. Bagaimana lingkungan ini diciptakan dengan menata unsur-unsurnya sehingga dapat mengubah perilaku siswa.

\section{Pembelajaran Interaktif}

Praktikum merupakan bentuk pengajaran yang kuat untuk membelajarkan keterampilan, pemahaman, dan sikap. Secara rinci praktikum dapat dimanfaatkan untuk [3]:

1) Melatih keterampilan-keterampilan yang dibutuhkan mahasiswa

2) Memberi kesempatan pada mahasiswa untuk menerapkan dan mengintegrasikan pengetahuan dan keterampilan yang dimilikinya secara nyata dalam praktek

3) Membuktikan sesuatu secara ilmiah atau melakukan scientific inquiry

4) Menghargai ilmu dan keterampilan dimiliki.

Praktikum adalah subsistem dari perkuliahan yang merupakan kegiatan terstruktur dan terjadwal yang memberi kesempatan kepada mahasiswa untuk mendapatkan pengalaman yang nyata dalam rangka meningkatkan pemahaman mahasiswa tentang teori atau agar mahasiswa menguasai keterampilan tertentu yang berkaitan dengan suatu pengetahuan atau suatu mata kuliah. Dalam merancang sistem pembelajaran, atau menyusun kurikulum, dosen dapat memasukan kegiatan praktikum/latihan/responsi dalam perencanaannya jika ada dukungan kuat bahwa materi mata kuliah hanya dapat dipahami kalau disertai praktikum/ responsi/latihan. 


\section{E. Embedded System}

Embedded system adalah sebuah aplikasi yang terdiri setidaknya dari sebuah pemprograman computer yang dapat diprogram kembali seperti sebuah Microcontroller, sebuah Microprocessor atau digital signal proseccor chip) yang akan digunakan pengguna sebagai tugas utamanya secara komputerisasi [11]. Embedded system atau sistem tertanam adalah alat elektronik yang membentuk sebuah komputer (microcontroller) dengan implementasi yang sudah ditentukan. Sebuah komputer digunakan sebagai alat utama dengan tujuan untuk menyederhanakan pola sistem dan menyediakan keguanaan khusus. Macam-macam penggunaan komputer [12]:

1) Komputer desktop (general purpose)

2) Information system (spesifik untuk mengolah informasi)

3) Embedded system (spesifik sebagai komponen produk lain)

Embeded system merupakan sebuah sistem (rangkaian elektronik) digital yang merupakan bagian dari sebuah sistem yang lebih besar, yang biasanya bukan berupa sistem elektronik. Kata embedded menunjukkan bagian yang tidak dapat berdiri sendiri yang merupakan application-specific system dirancang khusus untuk aplikasi tertentu. Embedded system dapat memberikan respon yang sifatnya real time [12].

\section{F. $W e b$}

Web merupakan file teks murni (plain text) yang berisi sintaks-sintaks HTML yang dapat diterjemahkan dengan internet browser. Sintaks HTML mampu memuat konten text, gambar, audio, video dan animasi [13]. Web based berjalan menggunakan basis teknologi web (internet) atau browser. Web based tidak banyak memerlukan program yang akan diinstal di sisi client. Keunggulannya adalah [13]:

1) Dapat menjalankan aplikasi berbasis web dimanapun kapanpun tanpa harus melakukan penginstalan.

2) Dapat dijalankan di sistem operasi manapun.

3) Dapat diakses lewat banyak media seperti: computer, handheld dan handphone yang sudah sesuai dengan standard WAP.

4) Tidak perlu spesifikasi computer yang tinggi untuk menggunakan aplikasi berbasis web ini, sebab di beberapa kasus sebagian besar proses dilakukan di web server penyedia aplikasi berbasis web.

Kekurangan:

1) Dibutuhkan koneksi intranet dan internet yang handal dan stabil. Hal ini bertujuan agar pada saat aplikasi dijalankan akan berjalan dengan baik dan lancar
2) Dibutuhkan sistem keamanan yang baik dikarenakan aplikasi dijalankan secara terpusat, sehingga apabila server di pusat down maka sistem aplikasi tidak bisa berjalan.

Internet adalah suatu jaringan komputer global yang terbentuk dari jaringan-jaringan lokal dan regional yang memungkinkan komunikasi data antar komputer yang terhubung ke jaringan tersebut. Internet merupakan hubungan antar berbagai jenis komputer dan jaringan di dunia yang berbeda sistem operasi maupun aplikasinya, dimana hubungan tersebut memanfaatkan kemajuan media komunikasi (telepon dan satelit) yang menggunakan protokol standar dalam berkomunikasi yaitu protokol TCP/IP. Web server merupakan suatu server internet yang menggunakan protokol HTTP (Hypertext Transfer Protocol). HTTP (Hypertext Transfer Protocol) untuk layanan World Wide Web (WWW) untuk melayani semua proses transferan data [13].

\section{METODOLOGI PENELITIAN}

Metode Monte Carlo merupakan dasar untuk semua algoritma dari metode simulasi yang didasari pada pemikiran penyelesaian suatu masalah untuk mendapatkan hasil yang lebih baik dengan cara memberi nilai sebanyak-banyaknya untuk mendapatkan ketelitian yang lebih tinggi. Simulasi adalah sebuah metode analitik yang bertujuan untuk membuat suatu imitasi dari sebuah sistem yang mempunyai sifat acak. Jika suatu sistem mengandung elemen yang mengikutsertakan faktor kemungkinan, model yang digunakan adalah model Monte Carlo. Dasar dari simulasi Monte Carlo adalah percobaan elemen kemungkinan dengan menggunakan sampel random (acak). Metode ini terbagi menjadi 10 tahap.

Tahapan-tahapan yang diperlukan dalam metode simulasi Monte Carlo adalah sebagai berikut:

1) Perumusan Masalah

Di tahap ini observasi masalah yang ada di lapangan. Penelitian kali ini terpusat pada kegiatan prakrikum pembelajaran embedded system, untuk selanjutnya menyimpulkan permasalahan dan kontribusi atau solusi.

2) Pengumpulan Data

Setelah menyimpulkan rumusan masalah yang akan diselesaikan tahap selanjutnya adalah pengumpulan data (requirement gathering), mengumpulkan atribut-atribut sistem aplikasi yang dibutuhkan dalam pengembangan sistem simulasi pembelajaran interaktif praktikum embedded system yang akan digunakan. 
3) Validasi Model

Perancangan model dibutuhkan utuk mempermudah penelitian menjadi sebuah acuan model dalam sistem yang nantinya model tersebut akan terus dikembangkan, selanjutnya adalah memvalidasi model aplikasi simulasi yang akan digunakan.

4) Mengembangkan Program Komputer dan Pengujian

Perancang model harus memutuskan bahasa pemrograman mana yang akan digunakan selanjutnya mengembangkan software simulasi berdasarkan model yang telah divalidasi, pada tahapan penulisan kode untuk pemprograman sistem tersebut.

5) Mengoperasikan Pilot Projek

Pilot projek dari software simulasi dioperasikan (run) untuk menguji model yang telah dibangun dalam komputer, bertujuan memvalidasi software yang dikembangkan.

6) Validasi Software

Pilot projek yang dioperasikan dapat digunakan untuk menguji kepekaan luaran model. Jika sistem menyerupai sistem yang ada, data luaran dari pengoperasian pilot projek dapat dibandingkan dengan sistem itu. Bila keselarasannya kurang cocok, model yang divalidasi dapat dimodifikasi agar mewakili sistem sebenarnya.

7) Merancang Eksperimen

Ditahapan ini dibutuhkan rancangan eksperimen yang mendeskripsikan kondisi awal operasi simulasi, panjang perioda, lama operasi, dan jumlah replikasi untuk membuat alternatif.

8) Operasi Produksi

Operasi produksi dilakukan untuk memproduksi kinerja data tentang rancangan sistem apakah sudah sesuai dengan operasi pada sistem yang terjadi di lapangan.

9) Analisis data Luaran

Tujuannya mengkonstruksi selang konfidensial dalam mengukur kinerja rancangan sistem, atau memutuskan apakah sistem yang disimulasikan itu relatif terbaik dari beberapa pengukuran kinerja tertentu.

10) Dokumentasi dan Implementasi Hasil

Model simulasi sering digunakan lebih dari satu aplikasi, hal ini penting untuk mendokumentasikan model dan program komputernya serta tahapan ini akan menjadi acuan untuk pengenbangan sistem selanjutnya.

\section{HASIL DAN PEMBAHASAN}

Pada tahapan pengumpulan dilakukan observasi dan studi literatur yang mendukung penelitian mengenai media pembelajaran interaktif berbasis web agar dapat mempermudah kegiatan praktikum embedded system dan memperkecil kerusakan alat dan komponen praktikum. Setelah mengetahui cara kerja komponen dan karaterisktiknya. Pengumpulan data dengan studi literature terlampir dalam daftar pustaka, yang mendukung perancangan media pembelajaran interaktif yang digunakan untuk mata kuliah embedded system yang terdiri dari teori dan praktek. Selanjutnya akan dihasilkan usulan perancangan media pembelajaran interaktif berbasis web.

\section{A. Sistem yang Berjalan}

Gambar 3 adalah rich picture yang menjelaskan sistem yang sedang berjalan saat ini, yang kegiatan praktikum masih menggunakan alat dan komponen nyata dengan resiko kerusakan alat. Dalam kegiatan praktikum saat ini masih menggunakan metode manual dalam implementasi kegiatannya.

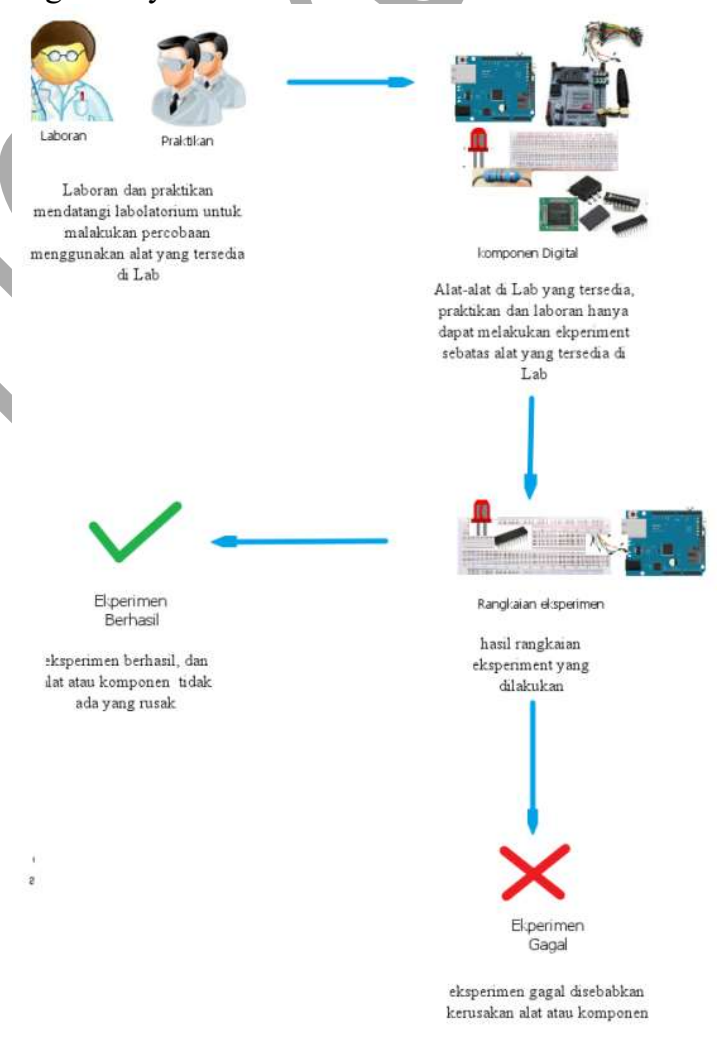

Gambar 3. Analisis yang Berjalan

B. Sistem yang Diusulkan

Rich picture menjelaskan sistem yang diusulkan ini, dengan tujuan menjadi media interaktik pembelajaran Embedded system dan memperkecil resiko kerusakan alat-alat di Laboratorium. Gambar 4 berisi sistem yang diusulkan. 


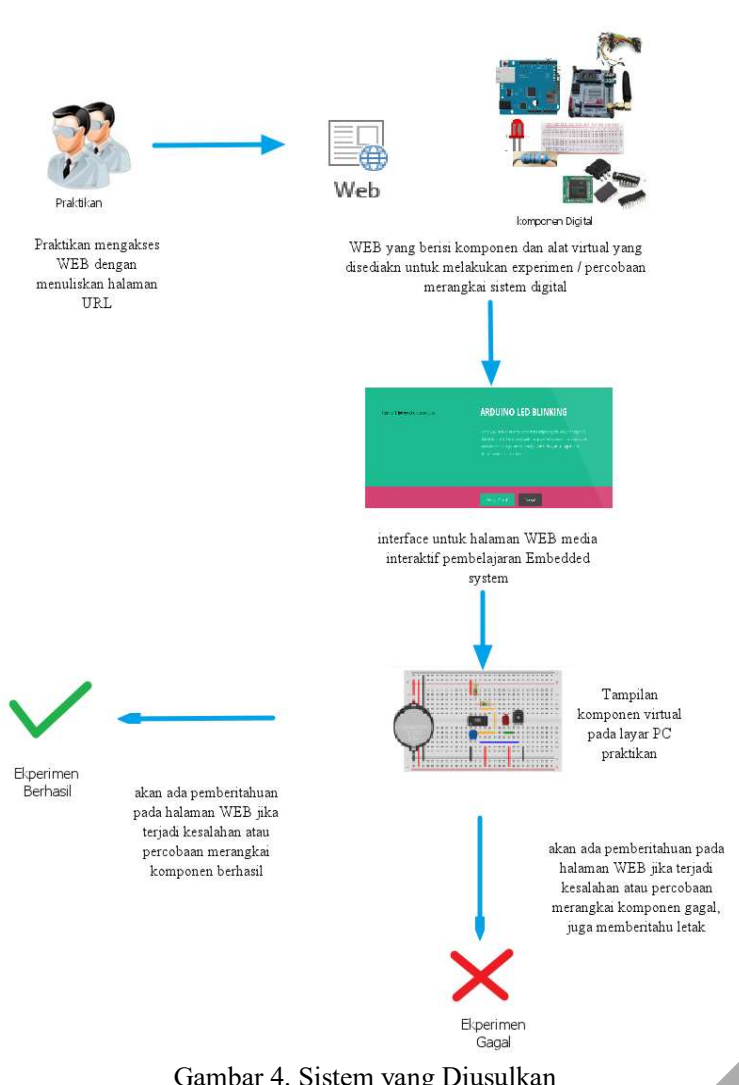

C. Validasi Model

Validasi model dijelaskan dengan Problems, Opportunities, Objectives and Constraints Matrix. Hasil analisis permasalahan dan peluang disebutkan secara lengkap pada matriks masalah, kesempatan, tujuan dan batasan (Problems, Opportunities, Objectives, and Constraints Matrix). Matriks ini dijabarkan dalam dua tabel yaitu analis sebab dan akibat (Cause and Effect Analysis) di Tabel 1 serta Tabel 2 berisi tujuan-tujuan perbaikan sistem (System Improvement Objectives). Cause and Effect Analysis merupakan sebuah teknik tempat masalahmasalah dipelajari untuk menentukan penyebabpenyebab dan akibat-akibatnya, sampai penyebab dan akibat tersebut tidak kembali menghasilkan gejala-gejala masalah yang lainnya. System Improvement Objectives memiliki tujuan yaitu untuk menentukan kriteria dimana semua perbaikan pada sistem akan diukur dan untuk mengidentifikasikan semua batasan yang membatasi fleksibilitas semua perbaikan tersebut. Berikut adalah tabel Cause dan Effect Analysis dan System Improvement Objectives pada sistem berjalan.

TABEL 1. CAUSE AND EFFECT

\begin{tabular}{|l|l|}
\hline \multicolumn{1}{|c|}{ Problem (Masalah) } & \multicolumn{1}{c|}{$\begin{array}{c}\text { Cause and Effects } \\
\text { (Sebab dan Akibat) }\end{array}$} \\
\hline Penggunaan & Cause $:$ karena tidak ada laboran \\
komponen/alat digital & yang mendampingi kegiatan \\
secara manual & praktikum \\
memperbesar resiko & Effect $:$ karena terbatasnya \\
kerusakan komponen & pengetahuan praktikan maka \\
\hline
\end{tabular}

\begin{tabular}{|l|l|}
\hline $\begin{array}{l}\text { jika tidak didampingi } \\
\text { oleh Laboran }\end{array}$ & $\begin{array}{l}\text { penggunaan alat akan dilakukan } \\
\text { sesuai dengan pengetahuannya } \\
\text { tidak sesuai standar data sheet } \\
\text { pada masing-masing alat/ } \\
\text { komponen }\end{array}$ \\
\hline $\begin{array}{l}\text { Laboran terbatas } \\
\text { dibandingkan dengan } \\
\text { lokal untuk melakukan } \\
\text { praktikum }\end{array}$ & $\begin{array}{l}\text { Cause: } \text { keterbatasan tenaga } \\
\text { laboran } \\
\text { Effect: } \text { sering terjadi kerusakan } \\
\text { komponen/alat dan tidak ada } \\
\text { pelaporan ke pihak pusat } \\
\text { laboratorium terpadu }\end{array}$ \\
\hline $\begin{array}{l}\text { Penggunaan } \\
\text { laboratorium terbatas } \\
\text { hanya saat ada mata } \\
\text { kuliah embedded } \\
\text { system atau jika ada } \\
\text { laboran yang berjaga }\end{array}$ & $\begin{array}{l}\text { Cause } \text { praktikum hanya dapat } \\
\text { dilakukan di Laboratorium } \\
\text { Effect: kurang maksimal } \\
\text { pembelajaran dan keterbatasan } \\
\text { penggunaan laboratorium }\end{array}$ \\
\hline $\begin{array}{l}\text { Keterbatasan alat yang } \\
\text { tersedia di } \\
\text { Laboratorium }\end{array}$ & $\begin{array}{l}\text { Cause: kelengkapan komponen } \\
\text { kurang } \\
\text { Effect: praktikum hanya terbatas } \\
\text { pada alat atau komponenyang } \\
\text { disediakan di Laboratorium }\end{array}$ \\
\hline
\end{tabular}

TABEL 2. OPPORTUNITIES (KESEMPATAN)

\begin{tabular}{|l|l|}
\hline \multicolumn{1}{|c|}{$\begin{array}{c}\text { Opportunities } \\
\text { (Kesempatan) }\end{array}$} & \multicolumn{1}{c|}{$\begin{array}{c}\text { Cause and Effects } \\
\text { (Sebab dan Akibat) }\end{array}$} \\
\hline $\begin{array}{l}\text { Sistem pembelajaran } \\
\text { interaktik untuk } \\
\text { praktikum embedded } \\
\text { system berbasis web }\end{array}$ & $\begin{array}{l}\text { Cause } \text { Sistem pembelajaran } \\
\text { interaktik untuk praktikum } \\
\text { embedded system berbasis WEB } \\
\text { dapat dilakuakn secara real time } \\
\text { dan dimana saja }\end{array}$ \\
& $\begin{array}{l}\text { Effect }: \text { meminimalisir kerusakan } \\
\text { alat di laboratorium dan } \\
\text { memberikan kesempatan pada } \\
\text { praktikan unutk dapat belajar } \\
\text { mandiri dan real-time }\end{array}$ \\
\hline
\end{tabular}

TABEL 3. SYSTEM IMPROVEMENT OBJECTIVES (TUJUAN-

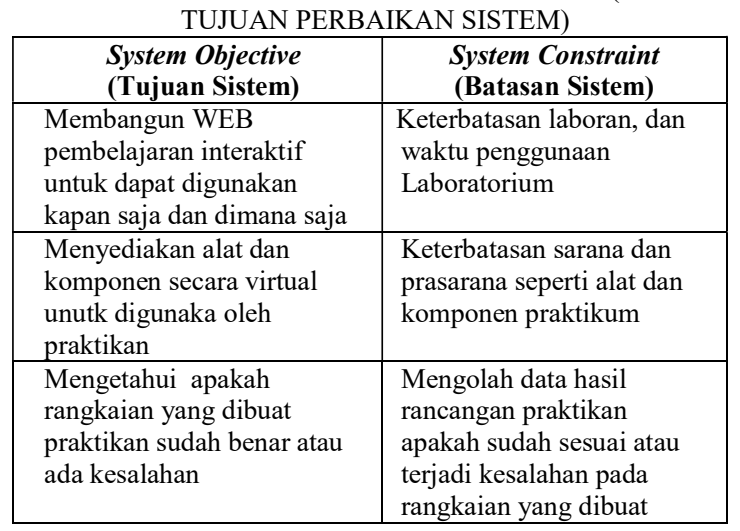

Kebutuhan sistem yang dijelaskan pada Tabel 3 sebagian besar merupakan hasil observasi peneliti sehingga diharapkan pembelajaran embedded system dapat lebih maksimal dan dapat dimanfaatkan sebaik-baiknya oleh praktikan.

\section{Rancangan Interface}

Perancangan antarmuka ini diharapkan dapat memudahkan pengguna halaman web dalam pengoperasiannya. Gambar 5 adalah halaman lembar kerja. Analisis luaran menggunakan pengujian mandiri seperti pada Tabel 4. 


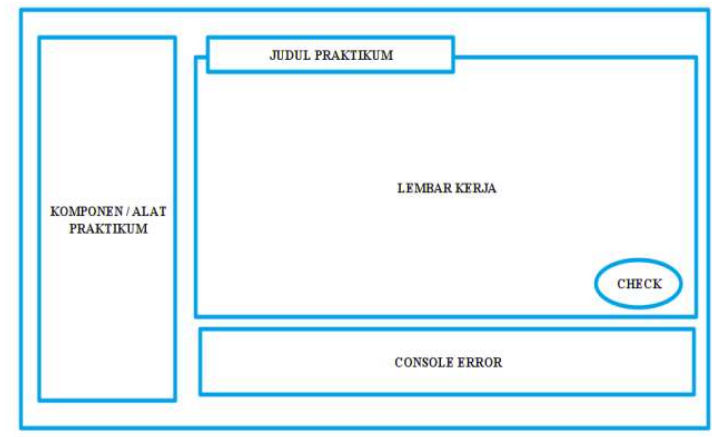

Gambar 5. Rancangan Halaman Lembar Kerja

TABEL 4. PENGUJIAN MANDIRI

\begin{tabular}{|c|c|c|c|c|}
\hline $\begin{array}{l}\mathbf{N} \\
\mathbf{0}\end{array}$ & Modul & Prasyarat & $\begin{array}{l}\text { Hasil yang } \\
\text { diharapkan }\end{array}$ & $\begin{array}{c}\text { Hasil } \\
\text { Uji } \\
\text { coba }\end{array}$ \\
\hline 1 & $\begin{array}{l}\text { Mengirim } \\
\text { data dari } \\
\text { halaman web } \\
\text { ke server }\end{array}$ & $\begin{array}{l}\text { Membutuhka } \\
\text { n koneksi } \\
\text { internet }\end{array}$ & $\begin{array}{l}\text { Data server } \\
\text { ter-update }\end{array}$ & OK \\
\hline 2 & $\begin{array}{l}\text { Mengecek } \\
\text { kesalahan } \\
\text { pada } \\
\text { rancangan }\end{array}$ & $\begin{array}{l}\text { Membutuhka } \\
\mathrm{n} \text { internet dan } \\
\text { pengaksesan } \\
\text { ke database }\end{array}$ & $\begin{array}{l}\text { Menunjukkan } \\
\text { hasil } \\
\text { perancangan } \\
\text { yang } \\
\text { dilakukan } \\
\text { benar atau } \\
\text { terdapat } \\
\text { kesalahan } \\
\end{array}$ & $\mathrm{OK}$ \\
\hline 3 & $\begin{array}{l}\text { Console error } \\
\text { menunjukan } \\
\text { bagian } \\
\text { kesalahan }\end{array}$ & $\begin{array}{l}\text { Mebutuhkan } \\
\text { koneksi } \\
\text { internet dan } \\
\text { plugin yang } \\
\text { digunakan } \\
\text { dapat berjalan } \\
\text { dengan baik } \\
\end{array}$ & $\begin{array}{l}\text { Pada layar } \\
\text { console error } \\
\text { menunjukkan } \\
\text { kesalahan } \\
\text { yang } \\
\text { dilakukan oleh } \\
\text { praktikan }\end{array}$ & \\
\hline 4 & $\begin{array}{l}\text { Halaman } \\
\text { lembar kerja } \\
\text { pada semua } \\
\text { komponen } \\
\text { virtual yang } \\
\text { tersedia dapat } \\
\text { digunakan } \\
\text { dengan baik }\end{array}$ & $\begin{array}{l}\text { Semua } \\
\text { komponen } \\
\text { dapat } \\
\text { memberikan } \\
\text { hasil yang } \\
\text { dihatapkan }\end{array}$ & $\begin{array}{l}\text { Semua button } \\
\text { pada } \\
\text { komponen } \\
\text { virtual dapat } \\
\text { digunakan dan } \\
\text { memberikan } \\
\text { perubahan } \\
\text { yang sesuai } \\
\text { dengan } \\
\text { komponen } \\
\text { yang } \\
\text { digunakan } \\
\end{array}$ & $\mathrm{OK}$ \\
\hline 5 & $\begin{array}{l}\text { Halaman } \\
\text { pertanyaan } \\
\text { dan jawaban } \\
\text { dapat } \\
\text { digunakan }\end{array}$ & $\begin{array}{l}\text { Mengharuska } \\
\text { n pengguna } \\
\text { menggunakan } \\
\text { email untuk } \\
\text { dapat } \\
\text { menggunakan } \\
\text { fungsi tanya } \\
\text { jawab }\end{array}$ & $\begin{array}{l}\text { Penanya dan } \\
\text { penjawab } \\
\text { dapat saling } \\
\text { berinteraksi } \\
\text { dan hasil } \\
\text { percakapan } \\
\text { dapat dilihat } \\
\text { di layar PC }\end{array}$ & $\mathrm{OK}$ \\
\hline
\end{tabular}

E. Pengoperasian Pilot project dan Validasi Software

Peneliti mulai merancang halaman web yang dimaksud dan memvalidasi fungsi-fungsi yang diimplementasikan pada halaman web tersebut pada Gambar 6 sampai 9. Tahapan ini merupakan langkah dari pengoperasian pilot project dan memvalidasi software.

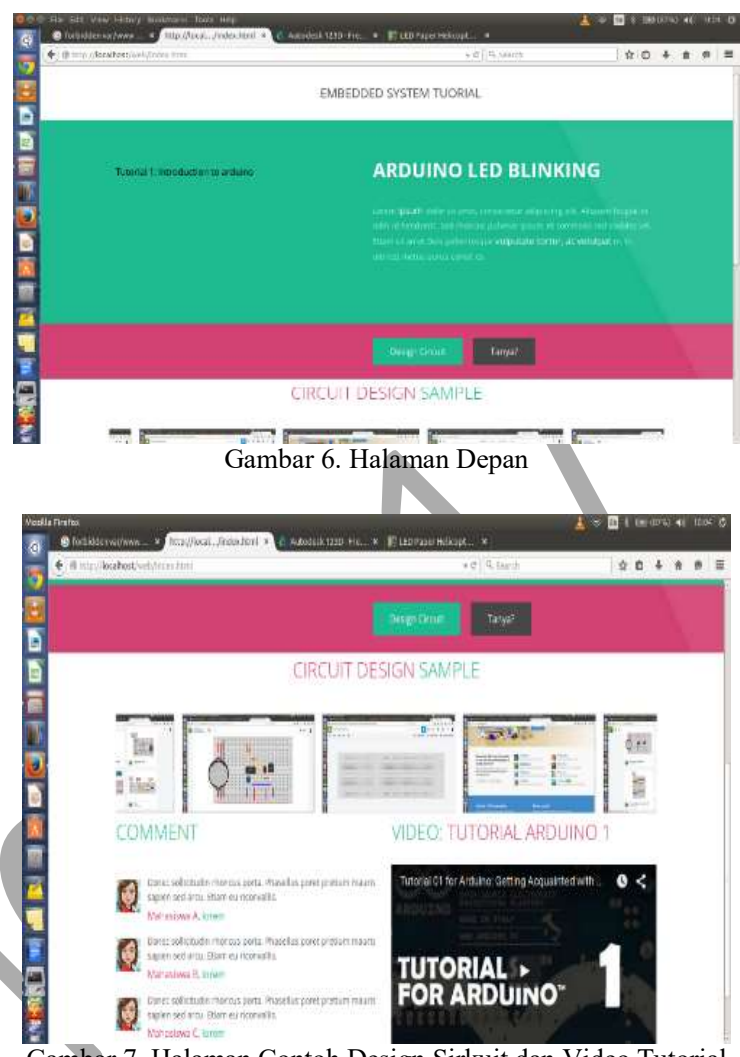

Gambar 7. Halaman Contoh Design Sirkuit dan Video Tutorial

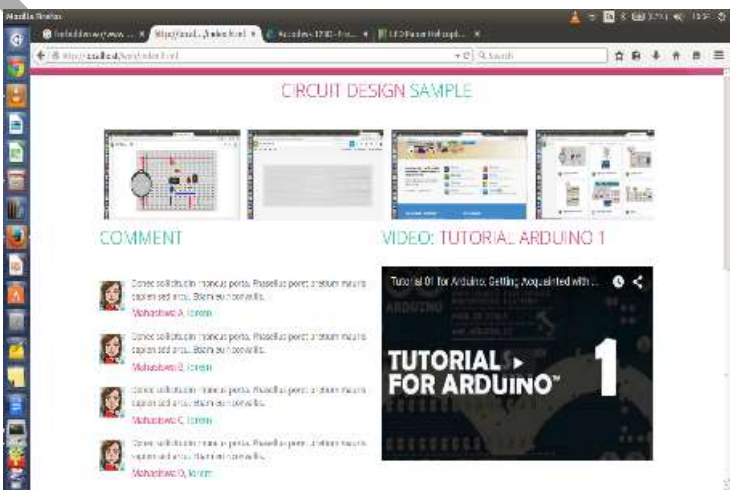

Gambar 8. Halaman Pertanyaan dan Jawaban

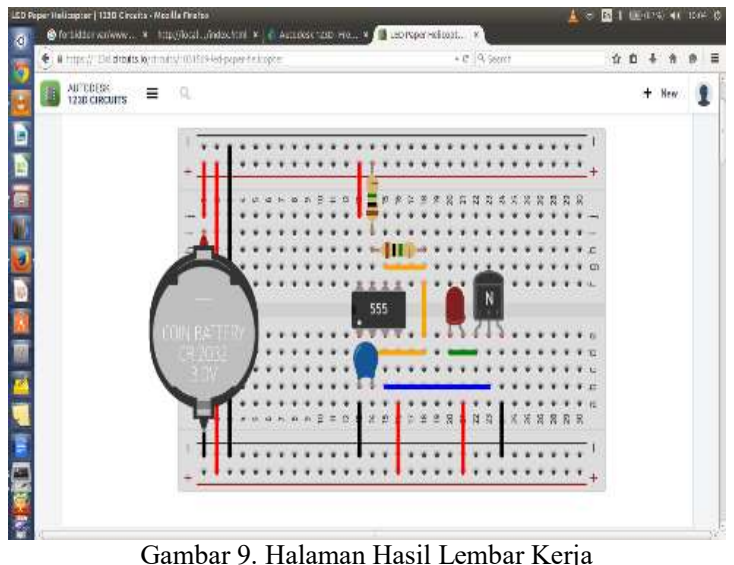

Gambar 9. Halaman Hasil Lembar Kerja 


\section{KESIMPULAN}

Setelah melakukan serangkaian penelitian didapat kesimpulan bahwa simulasi pembelajaran interaktif multimedia dapat dijadikan sebuah solusi untuk mengembangkan pembelajaran berbasis web. Keunggulannya adalah dapat dilakukan dimanapun dan kapanpun terutama untuk simulasi laboratorium yang dapat dijadikan sebagai cetak biru electromic laboratory.

\section{REFERENSI}

[1] Law, Averill M. dan Kelton W. David, Simulation, Modeling and Analysis, $2^{\text {nd }}$ Edition, McGraw-Hill International Edition, New York.

[2] Anggraini, MT . 2013. Buku Panduan Praktikum Embedded System, Sainstek, UIN Syarif Hidayatullah Jakarta.

[3] Floyd Jerome Gould. 1993. Introductory Science : "The basic idea of simulation.

[4] Sandi Setiawan. 1991. Teknik Pemrograman, Andi : Yogyakarta

[5] Dick, Walker \& Carey. Lou, Carey., James O. The systematic design ofInstruction (5th Ed). New York. Longman

[6] Law \& Kelton, 2000, dalam buku Simulation Modeling and Analysis 3 rd ,McGraw-Hill.
[7] Rubinstein, Reuven Y., 1991, Simulation and The Monte Carlo Method, John Wiley \& Sons, NewYoirk.

[6] Gagne, R, M. \& Briggs L.J. Principle of Instructional Design. New york: Holt,Rinehart \& Winston.

[7] Hendra Jaya, Jurnal Pendidikan Vokasi, Vol 2, Nomor 1, Februari 2012, Program studi Pend. Teknik Elektronika,FT Universitas Negeri Makassar,"Pengembangan Laboratorium Virtual untuk Kegiatan Praktikum dan Memfasititasi Pendidikan Karakter di SMK".

[8] Yayan Sunarya, Pemodelan Matematis dan Simulasi Monte Carlo: Proses Atom dalam Pengkasaran Permukaan kristal Muka (100), Tesis S-2, ITB, 1997.

[9] S. J. Mason, R. R. Hill, L. Mönch, O. Rose, T. Jefferson, J. W. Fowler eds introduction to monte carlo simulation. Proceedings of the 2008 Winter Simulation Conference diakses pada 27 September 2015 di http://www.informssim.org/wsc08papers/ 012.pdf.

[10] Depdiknas. Pendekatan Kontekstual, (Contekstual Teaching Learning/CTL). Jakarta: Depdiknas

[11] Bräunl, Thomas. Embedded Robotics - Mobile Robot Design and Applications with Embedded Systems, Second Edition. Springer, Jerman, Juni 2006.

[12] Byte Craft Limited. 2012. First Steps with Embedded Systems. Byte Craft Limited, Kanada.

[13] Betha Sidik, Ir. 2005. Pemrograman web dengan HTML. Informatika Bandung. 